\title{
Essential fatty acids in the liver and adipose tissue of genetically obese mice: effect of supplemental linoleic and $\gamma$-linolenic acids
}

\author{
BY S. C. CUNNANE, M. S. MANKU AND D. F. HOR ROBIN \\ Efamol Research Institute, PO Box 818, Kentville, Nova Scotia, Canada B4N 4 H8
}

(Received 29 February 1984 - Accepted 26 November 1984)

1. Genetically obese mice $(o b / o b)$ and their lean litter-mates were given diets iso-energetically supplemented with sucrose, hydrogenated coconut oil, safflower oil or evening primrose (Oenothera biennis) oil.

2. Weight gain over 15 weeks was significantly greater in the evening primrose oil-supplemented obese mice than in the other groups.

3. In all the groups of obese mice, liver total phospholipids contained proportionally less linoleic acid and more dihomo- $\gamma$-linolenic acid and arachidonic acid than did the lean controls.

4. As a percentage of total fatty acids, n-3 essential fatty acids (EFA) in liver and adipose tissue lipids were significantly lower in the obese mice than in the lean controls.

5. Supplementation with EFA-rich oils (safflower and evening primrose oil) increased the proportional composition of n-6 EFA and decreased the n-3 EFA more in the liver total phospholipids of the lean than the obese mice.

In the liver, de novo fatty acid synthesis has been shown to be inhibited by essential fatty acids (EFA) (Sabine et al. 1969; Bartley \& Abraham, 1972; Du \& Kruger, 1972; Jeffcoat et al. 1979). Fatty acids from both families of EFA $(n-6, n-3)$ appear to have similar effects in this regard without preference for either the chain length or number of double bonds in the fatty acid (Chu et al. 1969; Muto \& Gibson, 1969, 1970; Wahle \& Radcliffe, 1977; Schwarz \& Abraham, 1982). The effect of linoleic acid (18:2n-6) on fatty acid synthesis has been studied in detail and it has been shown to act at the level of the fatty acid synthetase complex (Flick et al. 1977). Synthesis and desaturation of palmitic (16:0) and stearic (18:0) acids have been shown to be increased in genetically obese rats and mice (Wahle, 1974; Rath $\&$ Thenen, 1980; Rath et al. 1981). The potency of inhibition of de novo fatty acid synthesis by saturated fatty acids and EFA varies depending on the tissue; EFA are more effective in the liver, whereas saturated fatty acids are more effective in adipose tissue (Waterman et al. 1975; Vernon, 1976).

Elevated 18:0 desaturation in obese mice has been shown to be significantly reduced by addition of maize oil to the diet (Enser \& Roberts, 1982). In humans (Oster et al. 1979) and in obese Zucker rats (Wahle, 1974), the level of obesity is inversely correlated with the level of 18:2n-6 in the adipose tissue. 18:2n-6 has been shown to be lower in subcutaneous fat of obese Zucker rats (Wahle, 1974) and Bar Harbor obese mice (Haessler \& Crawford, 1965; Winand et al.1968; Enser \& Ashwell, 1983). York and colleagues have shown that, in genetically obese mice bred in their laboratory, $18: 2 n-6$ was decreased and 20:4n-6 and 22:6n-3 were increased in hepatic membranes (York et al. 1982; French et al. 1983).

We have measured tissue lipid fatty acid composition including the C20 and C22 carbon fatty acids and assessed whether supplemental n-6 EFA may affect weight gain as well as the proportion of EFA in tissue lipids of obese mice. 
Table 1. Fatty acid composition ( $\mathrm{mg} / \mathrm{g}$ total fatty acids) of the oils and diets given to the genetically obese and lean mice

\begin{tabular}{|c|c|c|c|c|c|c|c|}
\hline \multirow[b]{2}{*}{ Fatty acid } & \multicolumn{3}{|c|}{ Oil* } & \multicolumn{4}{|c|}{ Diet* } \\
\hline & $\mathrm{HCO}$ & SFO & EPO & CTL & $\mathrm{HCO}$ & SFO & EPO \\
\hline $8: 0$ & 70 & - & - & - & 21 & - & - \\
\hline $10: 0$ & 60 & - & - & - & 33 & - & - \\
\hline $12: 0$ & 460 & - & - & - & 280 & - & - \\
\hline $14: 0$ & 185 & - & - & - & 116 & - & - \\
\hline $16: 0$ & 94 & 72 & 63 & 201 & 141 & 126 & 142 \\
\hline $16: 1 n-7$ & - & 2 & 1 & 31 & 15 & 15 & 19 \\
\hline 18:0 & 111 & 21 & 17 & 87 & 98 & 48 & 53 \\
\hline $18: 1 n-9$ & 15 & 105 & 100 & 304 & 144 & 198 & 217 \\
\hline $18: 2 n-6$ & - & 786 & 727 & 274 & 122 & 569 & 458 \\
\hline $18: 3 n-6 \dagger$ & - & - & 91 & - & - & - & 38 \\
\hline $18: 3 n-3$ & - & 7 & - & 33 & 13 & 16 & 16 \\
\hline $20: 4 n-6$ & - & - & - & 10 & 4 & 5 & 6 \\
\hline $22: 6 n-3$ & - & - & - & 9 & 4 & 4 & 6 \\
\hline
\end{tabular}

HCO, hydrogenated coconut oil; SFO, safflower oil; EPO, evening primrose oil; CTL, control (sucrose added before use).

* For details, see below.

$\dagger 18: 3 \mathrm{n}-6$ has the same retention time as $20: 0$.

\section{METHODS}

\section{Animals and diets}

Genetically obese mice (C57BL/6J,ob/ob) and their lean litter-mates $(o b /+)$ at 6 weeks of age were obtained from Jackson Laboratory (Bar Harbor, Maine, USA). Both the obese and lean control mice were housed in polypropylene cages and divided into groups of five mice each, all of which were given Purina rodent chow meal (no. 5001) and tap-water ad lib. The chow meal was iso-energetically supplemented with $(\mathrm{g} / \mathrm{kg}):(1) 120$ sucrose (SUC); (2) 50 hydrogenated coconut oil (HCO; Teklad Test Diets, Madison, WN), (3) 50 safflower oil (SFO, commercial source); or (4) 50 evening primrose oil (EPO, Efamol UK, Guildford, Surrey). Both obese and lean mice were given the same diets. These groups were designated obese (SUC), obese (HCO), obese (SFO), obese (EPO), lean (SUC), lean (HCO), lean (SFO), lean (EPO). The SFO- and EPO-supplemented groups were included for comparison of the effects of $18: 2 n-6$ alone (SFO) with 18:2n-6 and $\gamma$-linolenic acid (18:3n-6) combined (EPO). The sucrose- and the HCO-supplemented groups were energy controls; HCO since it is devoid of EFA and sucrose as a control for total energy intake.

Individual body-weights were measured weekly. Food intakes were measured during the last week of the experiment.

The fatty acid composition of the supplemental oils and final diets is shown in Table 1. The mice were given the respective diets for 15 weeks and, following $24 \mathrm{~h}$ starvation, were killed by diethyl ether anesthesia. The liver and the adipose tissue (subcutaneous fat and epididymal fat pad) were excised, weighed and frozen before lipid analysis.

\section{Lipid extraction and fatty acid analysis}

All solvents used in these procedures were certified reagent grade. The tissue samples (approximately $1 \mathrm{~g}$ ) were homogenized (Polytron, Brinkmann Instruments) in 20 vol. chloroform-methanol $(2: 1, \mathrm{v} / \mathrm{v})$ containing $0 \cdot 2 \mathrm{mg}$ butylated hydroxytoluene $/ 1$ as antiox- 


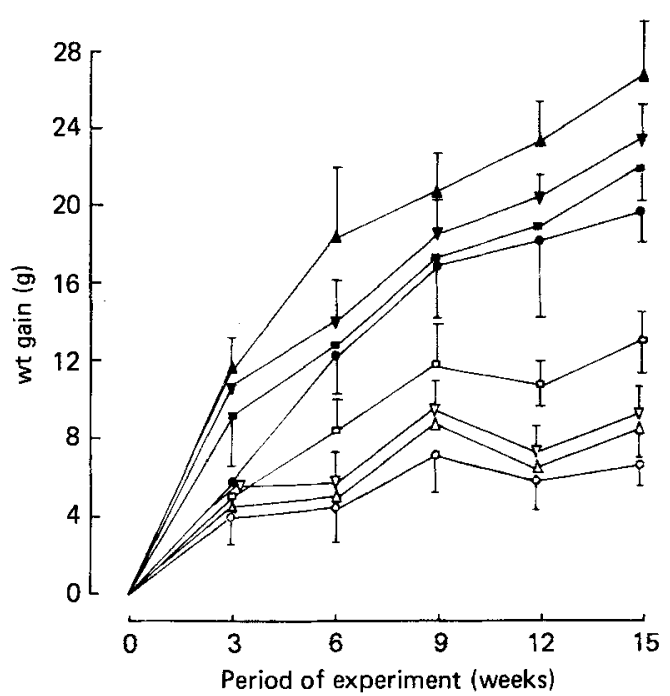

Fig. 1. Cumulative weight gain (g) of the obese and lean mice over 15 weeks. Each value represents the mean (standard deviations represented by vertical bars) for five mice. Diet of obese mice supplemented with ( $\square$ ) sucrose, (O) hydrogenated coconut oil, $(\boldsymbol{\nabla})$ safflower oil, $(\boldsymbol{A})$ evening primrose oil. Diet of lean mice supplemented with $(\square)$ sucrose, $(O)$ hydrogenated coconut oil, $(\nabla)$ safflower oil, $(\triangle)$ evening primrose oil. Obese mice given the diet supplemented with evening primrose oil gained more weight after 12 weeks than obese mice given the sucrose-supplemented diet $(P<0.05)$. Lean mice given the diet supplemented with sucrose gained more weight after 6 weeks than the other lean groups $(P<0.05)$.

idant. Triglycerides (TG) and total phospholipids (tPL) were separated by thin-layer chromatography on Merck 5765 silica gel G plates (BDH, Poole, Dorset) using the solvent system: light petroleum $\left(40-60^{\circ}\right)$-diethyl ether-acetic acid-methanol $(85: 15: 2 \cdot 5: 1$, by vol.). Silica bands containing the TG and TPL were scraped off the plates into screw-capped vials with Teflon-lined caps. The lipids were methylated with boron trifluoride (Chromatographic Specialities, Brockville, Ontario) at $70^{\circ}$ for $30 \mathrm{~min}$. The fatty acid methyl esters were extracted with hexane and analysed by gas-liquid chromatography (Hewlett Packard model 5880 ) using a $2 \mathrm{~m}$ glass column packed with $10 \%$ silar-10C on Gas Chrom Q 100/120 (Applied Science Division, State College, PA). The carrier gas was helium $(30 \mathrm{ml} / \mathrm{min})$. The oven temperature was programmed to rise from $165^{\circ}$ to $190^{\circ}$ at $2^{\circ} / \mathrm{min}$. The detector temperature was set at $220^{\circ}$. Retention times and peak areas were automatically computed by an integrator (level 4, Hewlett Packard). Fatty acid peaks were identified by comparison with standard fatty acid methyl esters (Nu-Chek Prep, Elysian, MN).

\section{Statistics}

Two-way analysis of variance (ANOVA) and Student's $t$ test were used to make statistical comparisons.

\section{RESULTS}

Growth curves and tissue weights

After 12 weeks, the obese (EPO) mice had gained significantly more weight than the obese (SUC) or obese $(\mathrm{HCO})$ mice $(P<0.05)$ (Fig. 1). The amount of weight gained by the obese (SUC) or obese (SFO) mice was not significantly different over the 15 week period. Among the groups of lean mice, the lean (SUC) group gained more weight than the HCO-, SFO- 
Table 2. Tissue weights $(g)$ of obese $(O B)$ and lean $(L N)$ mice given diets iso-energetically supplemented with sucrose (SUC), hydrogenated coconut oil (HCO), safflower oil (SFO) or evening primrose oil $(E P O) \ddagger$

(Values are means and standard deviations for five samples)

\begin{tabular}{|c|c|c|c|c|c|c|c|c|}
\hline & \multicolumn{2}{|c|}{ SUC } & \multicolumn{2}{|c|}{$\mathrm{HCO}$} & \multicolumn{2}{|c|}{ SFO } & \multicolumn{2}{|c|}{ EPO } \\
\hline & Mean & SD & Mean & SD & Mean & $\mathrm{SD}$ & Mean & $\mathrm{SD}$ \\
\hline \multicolumn{9}{|l|}{ Liver } \\
\hline OB & 5.8 & $0 \cdot 8$ & $4 \cdot 9^{*}$ & $0 \cdot 5$ & $4 \cdot 9^{*}$ & 0.4 & $4 \cdot 7^{*}$ & 0.9 \\
\hline LNi† & 1.7 & $0 \cdot 2$ & $1.4^{*}$ & 0.04 & 1.6 & 0.1 & 1.6 & $0 \cdot 1$ \\
\hline \multicolumn{9}{|c|}{ Epididymal fat } \\
\hline $\mathrm{OB}$ & 1.2 & 0.5 & 1.0 & 0.2 & 0.9 & $0 \cdot 1$ & 1.0 & $0 \cdot 1$ \\
\hline $\mathrm{LN}+t$ & 0.4 & 0.1 & 0.4 & $0 \cdot 1$ & 0.5 & $0 \cdot 1$ & 0.6 & $0 \cdot 1$ \\
\hline
\end{tabular}

Mean values for HCO, SFO and EPO were significantly different from those of SUC for both OB and LN mice (ANOVA and Student's $t$ test): ${ }^{*} P<0.05$.

Mean values of $\mathrm{OB}$ and LN groups as a whole were significantly different (ANOVA): $\dagger+P<0 \cdot 01$.

$\$$ For details of diets and supplements, see Table 1 and p. 442.

or EPO-supplemented groups after 6 weeks $(P<0.05)$ (Fig. 1). The weight gains of the lean mice supplemented with $\mathrm{HCO}$, SFO or EPO did not differ throughout the experiment.

Food intake in two consecutive $24 \mathrm{~h}$ periods was measured in mice from each group. No significant effect of diet existed but obese mice consumed significantly more food than the lean mice $(6.0$ v. $4.0 \mathrm{~g} / \mathrm{d}, P<0.01)$.

The obese mice as a whole weighed almost twice as much as the lean mice after 15 weeks yet, compared with the lean mice, the absolute weights of the heart, kidney and testes were not increased in any of the groups of obese mice (results not shown). Rather, the body-weight increase was apparently confined to the liver and adipose tissue (Table 2). In both the lean controls and the obese mice, the liver weight: body-weight value was lower in the SFO- and EPO-supplemented groups compared with the SUC or HCO groups $(P<0 \cdot 05)$. Epididymal fat weight:body-weight value was greater in the lean (SFO) and lean (EPO) groups compared with both the lean (SUC) group $(P<0.05)$ and the obese (SFO) or obese (EPO) groups $(P<0.01)$.

\section{Tissue lipid composition}

The following differences between groups refer exclusively to proportional changes in fatty acid composition, i.e. to changes in the concentration of individual fatty acids in the lipid fraction.

Liver $t P L$. Overall, the obese mice had proportionally less 16:0 but had more 18:0 and oleic acid $(18: \ln -9)$ in the liver tPL than did the lean mice. These differences were not significantly affected by supplementation with HCO, SFO or EPO (Table 3). In the liver tPL, the obese (SUC) mice had proportionally less $18: 2 n-6,18: 3 n-6$ and docosapentaenoic acid $(22: 5 n-6)$ but more dihomo- $\gamma$-linolenic acid $(20: 3 n-6)$ and arachidonic acid $(20: 4 n-6)$ than the lean (SUC) mice (results not shown for 18:3n-6, 22:5n-6). The obese mice supplemented with SFO or EPO did not accumulate as much $18: 2 n-6,18: 3 n-6$ or $20: 4 n-6$ but accumulated more 22:4n-6 and 22:5n-6 (results not shown) than the lean mice given these supplements. The obese mice had proportionally less total $\mathbf{n}-3$ EFA than the lean mice irrespective of dietary treatment. $\alpha$-Linolenic acid $(18: 3 n-3)$ was present in the lean mice (3-4 mg/g total fatty acids) but was only detected in the obese mice in trace amounts (results not shown). Compared with their respective control groups, the n-3 EFA in the obese (SFO) 
Table 3. Fatty acid composition ( $\mathrm{mg} / \mathrm{g}$ total fatty acids) of liver total phospholipids from obese $(O B)$ and lean $(L N)$ mice fed on diets iso-energetically supplemented with sucrose $(S U C)$, hydrogenated coconut oil (HCO), safflower oil (SFO) or evening primrose oil (EPO) $\ddagger$

(Values are means and standard deviations for five samples)

\begin{tabular}{|c|c|c|c|c|c|c|c|c|c|}
\hline \multirow{2}{*}{$\begin{array}{l}\text { Fatty } \\
\text { acid }\end{array}$} & & \multicolumn{2}{|c|}{ SUC } & \multicolumn{2}{|c|}{$\mathrm{HCO}$} & \multicolumn{2}{|c|}{ SFO } & \multicolumn{2}{|c|}{ EPO } \\
\hline & & Mean & $\mathrm{SD}$ & Mean & SD & Mean & $\mathrm{SD}$ & Mean & SD \\
\hline \multirow[t]{2}{*}{$16: 0$} & $\mathrm{OB}$ & 191 & 3 & 189 & 3 & $167^{* * *}$ & 6 & 177 & 6 \\
\hline & LN†† & 228 & 6 & 222 & 6 & $210^{* *}$ & 4 & $196^{* *}$ & 7 \\
\hline \multirow[t]{2}{*}{ 18:0 } & $\mathrm{OB}$ & 167 & 4 & 174 & 21 & $181^{*}$ & 17 & $206^{*}$ & 11 \\
\hline & LN† & 142 & 7 & 143 & 12 & $163^{*}$ & 5 & $168^{* *}$ & 4 \\
\hline \multirow{2}{*}{$18: \ln -9$} & $\mathrm{OB}$ & 154 & 5 & $127^{*}$ & 23 & $108^{* *}$ & 7 & $102^{* *}$ & 9 \\
\hline & $\mathrm{LN}+\dagger$ & 111 & 4 & 100 & 17 & $81^{* *}$ & 1 & $76^{* *}$ & 1 \\
\hline \multirow[t]{2}{*}{$18: 2 n-6$} & $\mathrm{OB}$ & 100 & 7 & 104 & 17 & $118^{* *}$ & 8 & $100^{* *}$ & 4 \\
\hline & LN+† & 149 & 4 & 153 & 19 & $190^{* *}$ & 6 & $175^{* *}$ & 5 \\
\hline \multirow[t]{2}{*}{$20: 3 n-6$} & $\mathrm{OB}$ & 40 & 2 & $36^{*}$ & 2 & $33^{*}$ & 3 & 36 & 3 \\
\hline & LN+† & 18 & 1 & 16 & 4 & 16 & 1 & 18 & 1 \\
\hline \multirow[t]{2}{*}{$20: 4 n-6$} & OB & 190 & 7 & 202 & 28 & $243^{* *}$ & 20 & $241^{* *}$ & 8 \\
\hline & LN+† & 143 & 7 & 140 & 11 & $176^{* *}$ & 9 & $204^{* *}$ & 6 \\
\hline \multirow[t]{2}{*}{$20: 5 n-3$} & OB & 1 & 0.1 & $5^{* *}$ & 0.2 & 2 & $0 \cdot 1$ & 1 & 0.1 \\
\hline & LN+† & 13 & 1 & 14 & 3 & $4^{* *}$ & 1 & $3^{* *}$ & $0 \cdot 2$ \\
\hline \multirow[t]{2}{*}{$22: 5 n-3$} & OB & 2 & 0.4 & $5^{*}$ & 0.4 & 4 & 0.4 & $4^{* *}$ & 0.4 \\
\hline & $\mathrm{LN}+\dagger$ & 7 & 0.2 & 7 & 1 & $5 * *$ & 1 & $4 * *$ & 0.2 \\
\hline \multirow[t]{2}{*}{$22: 6 n-3$} & OB & 145 & 4 & 143 & 13 & 129 & 14 & 116 & 3 \\
\hline & $\mathrm{LN}+\dagger$ & 165 & 9 & 176 & 17 & $130^{* *}$ & 3 & $128^{* *}$ & 3 \\
\hline
\end{tabular}

Mean values for $\mathrm{HCO}, \mathrm{SFO}$ and EPO were significantly different from SUC in both OB and LN mice (ANOVA and Student's $t$ test): ${ }^{*} P<0.05,{ }^{* *} P<0.01$.

Mean values for $\mathrm{OB}$ and $\mathrm{LN}$ groups as a whole were significantly different (ANOVA) : $\uparrow P<0.05$, $\dagger \dagger P<0.01$.

$\ddagger$ For details of diets and supplements, see Table 1 and p. 442 .

and obese (EPO) mice did not decrease as much as in the lean (SFO) and lean (EPO) mice (Table 3).

Liver TG. Compared with the lean mice, palmitoleic acid $(16: 1 \mathrm{n}-7)$ and $18: 1 \mathrm{n}-9$ in the obese mice were proportionally higher but 18:0 was lower (Table 4). Proportionally, total n- 6 and n-3 EFA were all significantly lower in the liver TG of the obese mice than in the lean mice, an effect partially inhibited by EPO or SFO supplementation. The increase in the percentage composition of $18: 2 n-6,20: 3 n-6$ and $20: 4 n-6$ in the obese (SFO) and obese (EPO) group compared with the obese (SUC) group was greater than in the lean mice. However, the decrease in 18:1n-9 was greater in the lean (SFO) and (EPO) than in the obese (SFO) and (EPO) mice.

Epididymal fat TG. In the lean mice, subcutaneous fat was not present in amounts sufficiently large for lipid analysis. In both lean and obese mice, the fatty acid composition of the epididymal and subcutaneous fat was very similar. Since fatty acid values for the subcutaneous fat from the lean mice were not available, only the values for the epididymal fat are presented (Table 5). In the epididymal fat TG of the obese mice as a whole, 16:0, 18:0 and the total EFA (n-6 and $n-3)$ were lower but 18: $\ln -9$ was higher than in the lean mice. 18:2n-6 increased to a greater extent in the lean (SFO) and lean (EPO) mice than in the obese (SFO) and obese (EPO) mice. 
Table 4. Fatty acid composition ( $\mathrm{mg} / \mathrm{g}$ total fatty acids) of liver triglycerides from obese $(O B)$ and lean $(L N)$ mice fed on diets iso-energetically supplemented with sucrose (SUC), hydrogenated coconut oil (HCO), safflower oil (SFO) or evening primrose oil (EPO) $\ddagger$

(Values are means and standard deviations for five samples)

\begin{tabular}{|c|c|c|c|c|c|c|c|c|c|}
\hline \multirow{2}{*}{$\begin{array}{l}\text { Fatty } \\
\text { acid }\end{array}$} & & \multicolumn{2}{|c|}{ SUC } & \multicolumn{2}{|c|}{$\mathrm{HCO}$} & \multicolumn{2}{|c|}{ SFO } & \multicolumn{2}{|c|}{ EPO } \\
\hline & & Mean & SD & Mean & SD & Mean & SD & Mean & SD \\
\hline \multirow[t]{2}{*}{$16: 0$} & $\mathrm{OB}$ & 239 & 4 & 234 & 5 & 219 & 3 & 216 & 8 \\
\hline & LN & 239 & 9 & 236 & 13 & $222^{* *}$ & 6 & $198^{* *}$ & 14 \\
\hline \multirow[t]{2}{*}{$16: \ln -7$} & $\mathrm{OB}$ & 126 & 13 & 108 & 6 & $94^{* *}$ & 7 & $102^{* *}$ & 4 \\
\hline & $\mathrm{LN}+\phi$ & 48 & 8 & 43 & 14 & $26^{* *}$ & 3 & $23^{* *}$ & 2 \\
\hline \multirow[t]{2}{*}{ 18:0 } & $\mathrm{OB}$ & 9 & 1 & 10 & 1 & 8 & 2 & 8 & 1 \\
\hline & $\mathrm{LN}+\dagger$ & 18 & 5 & 29 & 15 & 22 & 2 & 23 & 4 \\
\hline \multirow{2}{*}{$18: \ln -9$} & $\mathrm{OB}$ & 533 & 9 & 507 & 14 & 441 & 15 & 428 & 15 \\
\hline & LN+† & 393 & 48 & 358 & 27 & $238^{* *}$ & 9 & $221^{* *}$ & 8 \\
\hline \multirow[t]{2}{*}{$18: 2 n-6$} & $\mathrm{OB}$ & 69 & 5 & 84 & 8 & $182^{* *}$ & 7 & $199 * *$ & 13 \\
\hline & $\mathrm{LN}+\dagger$ & 220 & 28 & 204 & 8 & $392^{* *}$ & 7 & $418^{* *}$ & 22 \\
\hline \multirow[t]{2}{*}{$20: 3 n-6$} & OB & 2 & 0.1 & 3 & 0.4 & $7 * *$ & 1 & $11^{* *}$ & 1 \\
\hline & LNtt & 6 & 0.4 & 7 & 3 & $8^{* *}$ & 0.4 & $22^{* * *}$ & 2 \\
\hline \multirow[t]{2}{*}{$20: 4 n-6$} & $\mathrm{OB}$ & 3 & 1 & 4 & 1 & $9^{* *}$ & 1 & $13^{* *}$ & 1 \\
\hline & LNI† & 14 & 1 & 24 & 15 & $23^{* *}$ & 2 & $22^{* *}$ & 2 \\
\hline \multirow[t]{2}{*}{$22: 6 n-3$} & $\mathrm{OB}$ & 7 & 2 & 9 & 2 & 10 & 2 & $11^{*}$ & 1 \\
\hline & LN $+\dagger$ & 38 & 11 & 56 & 18 & 30 & 5 & 31 & 3 \\
\hline
\end{tabular}

Mean values for HCO, SFO and EPO were significantly different from SUC in both OB and LN mice (ANOVA and Student's $t$ test): ${ }^{*} P<0.05,{ }^{* *} P<0.01$.

Mean values of the $\mathrm{OB}$ and $\mathrm{LN}$ groups as a whole were significantly different (ANOVA): $\dagger \dagger P<0 \cdot 01$.

$\$$ For details of diets and supplements, see Table 1 and p. 442.

Table 5. Fatty acid composition ( $\mathrm{mg} / \mathrm{g}$ total fatty acids) of epididymal fat pad triglycerides from obese $(O B)$ and lean $(L N)$ mice fed on diets iso-energetically supplemented with sucrose $(S U C)$, hydrogenated coconut oil $(H C O)$, safflower oil (SFO) or evening primrose oil (EPO) $\ddagger$

(Values are means and standard deviations for five samples)

\begin{tabular}{|c|c|c|c|c|c|c|c|c|c|}
\hline \multirow{2}{*}{$\begin{array}{c}\text { Fatty } \\
\text { acid }\end{array}$} & & \multicolumn{2}{|c|}{ SUC } & \multicolumn{2}{|c|}{$\mathrm{HCO}$} & \multicolumn{2}{|c|}{ SFO } & \multicolumn{2}{|c|}{ EPO } \\
\hline & & Mean & SD & Mean & SD & Mean & SD & Mean & SD \\
\hline \multirow[t]{2}{*}{$16: 0$} & OB & 186 & 8 & 186 & 5 & $162^{* *}$ & 1 & $163^{* *}$ & 6 \\
\hline & $\mathrm{LN}+\dagger$ & 199 & 4 & $170^{* *}$ & 2 & $144^{* *}$ & 3 & $138^{* *}$ & 9 \\
\hline \multirow[t]{2}{*}{$16: 1 n-7$} & $\mathrm{OB}$ & 79 & 12 & 90 & 5 & $55^{* *}$ & 3 & $56^{* *}$ & 6 \\
\hline & LN & 90 & 7 & 84 & 18 & $45^{* * *}$ & 5 & $48^{* *}$ & 2 \\
\hline \multirow[t]{2}{*}{$18: 0$} & OB & 17 & 2 & 17 & 1 & 16 & 1 & 17 & 2 \\
\hline & LN+† & 22 & 1 & 30 & 7 & 24 & 2 & 22 & 2 \\
\hline \multirow[t]{2}{*}{$18: 1 n-9$} & OB & 505 & 34 & 470 & 8 & $393^{* *}$ & 22 & $379^{* *}$ & 22 \\
\hline & LNH† & 422 & 20 & 419 & 21 & $331^{* * *}$ & 9 & $316^{* *}$ & 7 \\
\hline \multirow[t]{2}{*}{$18: 2 n-6$} & OB & 179 & 17 & 187 & 11 & $343^{* *}$ & 1 & $346^{* *}$ & 21 \\
\hline & LN & 196 & 27 & 183 & 11 & $410^{* *}$ & 12 & $416^{* *}$ & 15 \\
\hline \multirow[t]{2}{*}{$18: 3 n-3$} & OB & 10 & 1 & 9 & $0 \cdot 3$ & $8^{*}$ & 0.4 & $7^{*}$ & $0 \cdot 2$ \\
\hline & $\mathrm{LN}+\phi$ & 20 & 1 & 19 & 4 & $14^{* *}$ & 1 & $14^{* *}$ & 1 \\
\hline
\end{tabular}

Mean values for HCO, SFO and EPO were significantly different from SUC in both OB and LN mice (ANOVA and Student's $t$ test): ${ }^{*} P<0.05, * * P<0.01$.

Mean values for OB and LN groups as a whole differed significantly (ANOVA): $\dagger^{*} P<0.01$.

$\$$ For details of diets and supplements, see Table 1 and p. 442 . 


\section{DISCUSSION}

Our results indicate that, compared with the fatty acid composition in the lean (SUC) mice, proportionally, $18: 2 n-6$ was lower but $20: 3 n-6$ and $20: 4 n-6$ were higher in the liver tPL of the obese mice. These results confirm those from other laboratories reporting results on Bar Harbor $o b / o b$ mice (Haessler \& Crawford, 1965; Winand et al. 1968; York et al. 1982). In addition, in both liver and adipose tissue, the total proportion of n-3 EFA was significantly lower in the obese than in the lean mice. Our results on n-3 EFA contrast with those of York et al. (1982) and French et al. (1983) who have observed elevated 22:6n-3.

Both the lean and obese mice were divided into groups to assess the effect of supplemental dietary EFA on proportional tissue fatty acid composition. Since previous reports have demonstrated an inhibitory effect of EFA on fatty acid synthesis in the liver (Muto \& Gibson, 1969; Du \& Kruger, 1972; Flick et al. 1977), it was hypothesized that supplemental EFA might decrease the rate of weight gain in obese mice. However, EPO significantly and SFO non-significantly increased weight gain in obsese but not in lean mice. The obese (EPO) and (SFO) mice had smaller livers and epididymal fat pads than the obese (SUC) mice, suggesting that the increased weight gain in the former groups was probably confined to subcutaneous fat.

The major differences in the proportional fatty acid composition of the liver TPL and TG between obese and lean mice were not significantly affected by supplementation with $\mathrm{HCO}$, SFO or EPO, e.g. compared with the groups of lean mice, $18: 2 n-6$ and total n-3 EFA remained lower and 20:3n-6 and 20:4n-6 remained higher in all the groups of obese mice.

Since the ratios, $18: 2 n-6 / 20: 3 n-6$ and $18: 2 n-6 / 20: 4 n-6$ were increased in the tPL of the obese mice, $\delta-6$ desaturation of $18: 2 n-6$ was probably increased in the obese mice (Hill et al. 1982). 18:2n-6 and 18:3n-3 compete as substrates for the $\delta-6$ desaturase (Holman, 1971). If increased desaturation of $18: 2 n-6$ occurred at the expense of $18: 3 n-3$ desaturation, 18:3n-3 should have been elevated in the liver tPL of the obese mice. This was not the case, in fact 18:3n-3 was only detectable in the liver tPL from obese mice in trace amounts, suggesting that other aspects of n-3 EFA metabolism apart from $\delta-6$ desaturation of $18: 3 n-3$ were abnormal in the obese mice, e.g. oxidation, absorption.

In the liver TG of obese mice, the EFA supplements did not cause as significant a decrease in the proportion of non-EFA $(16: 0,16: 1 n-7,18: 1 n-9)$ as occurred in the lean mice fed on EFA. Conversely, the proportion of $n-6$ EFA did not increase as much in the lean as in the obese mice supplemented with EFA (Table 4). Therefore, n-6 EFA in the diet appear more readily to displace non-EFA in the liver TG of the obese than of the lean mice. A largely similar effect occurred in the epididymal-fat TG; proportionally, non-EFA decreased more significantly in the lean than in the obese mice supplemented with EFA (Table 5).

Our results therefore raise three questions. (1) Based on proportional fatty acid composition, liver TG of the obese mice accumulated dietary n-6 EFA more rapidly, but the liver tPL accumulated n-6 EFA more slowly, than in the lean mice. Therefore, is there an abnormality in n-6 EFA transfer from TG to tPL in genetically obese mice and does this account for the increased weight gain in the obese (EPO) mice? (2) The percentage composition of n-3 EFA was significantly lower in liver and adipose tissue lipids of obese mice. Therefore, is relative n-3 EFA deficiency significantly related to the development of obesity in these mice? (3) Does the low level of n-3 EFA account for the apparent increase in desaturation of $18: 2 n-6$ in the liver of the obese mice?

S.C.C. was an Industrial Research Fellow of the National Research Council of Canada while this research was conducted. Excellent technical assistance was provided by M.A. Ryan, N. Morse and V. Kyte. 


\section{REFERENCES}

Bartley, J. C. \& Abraham, S. (1972). Biochimica et Biophysica Acta 280, 258-266.

Chu, L. C., McIntosh, D. J., Hincenbergs, I. \& Williams, M. A. (1969). Biochimicaet Biophysica Acta 187, 573-575.

Du, J. T. \& Kruger, F. A. (1972). Journal of Nutrition 102, 1033-1038.

Enser, M. \& Ashwell, M. (1983). Lipids 18, 776-780.

Enser, M. \& Roberts, J. L. (1982). Biochemical Journal 206, 561-570.

Flick, P. K., Chen, J. \& Vagelos, P. R. (1977). Journal of Biological Chemistry 252, 4242-4249.

French, R. R., York, D. A., Portman, J. M. \& Isaacs, K. (1983). Comparative Biochemistry and Physiology 76B, 309-319.

Haessler, H. A. \& Crawford, J. D. (1965). Annals of the New York Academy of Sciences 131, 476-484.

Hill, E. G., Johnson, S. B., Lawson, L. D., Mafouz, M. M. \& Holman, R. T. (1982). Proceedings of the National Academy of Sciences, USA 79, 953-957.

Holman, R. T. (1971). In Progress in the Chemistry of Fats and Other Lipids, pp. 275-348 [R. T. Holman, editor]. New York: Pergamon.

Jeffcoat, R., Roberts, P. A. \& James, A. T. (1979). European Journal of Biochemistry 101, 447-454.

Muto, Y. \& Gibson, D. M. (1969). Federation Proceedings 28, 882.

Muto, Y. \& Gibson, D. M. (1970). Biochemical and Biophysical Research Communications 38, 9-15.

Oster, P., Arab, L. \& Schellenberg, B. (1979). Research in Experimental Medicine 175, 287-291.

Rath, E. A., Hems, D. A. \& Beloff-Chain, A. (1981). Diabetologica 18, 507-511.

Rath, E. A. \& Thenen, S. W. (1980). Biochimica et Biophysica Acta 618, 18-27.

Sabine, J. R., McGrath, H. \& Abraham, S. (1969). Journal of Nutrition 98, 312-318.

Schwarz, R. S. \& Abraham, S. (1982). Biochimica et Biophysica Acta 711, 316-326.

Vernon, R. G. (1976). Lipids 11, 662-669.

Wahle, K. W. J. (1974). Comparative Biochemistry and Physiology 48B, 565-574.

Wahle, K. W. J. \& Radcliffe, J. D. (1977). Lipids 12, 135-139.

Waterman, R. A., Romsos, D. R., Tsai, A. C., Miller, E. R. \& Leveille, G. A. (1975). Proceedings of the Society for Experimental Biology and Medicine 150, 347-351.

Winand, J., Furnelle, J. \& Christophe, J. (1968). Biochimica et Biophysica Acta 152, 280-289.

York, D. A., Hyslop, P. A. \& French, R. R. (1982). Biochemical and Biophysical Research Communications 106, 1479-1483. 